\title{
Gastric-resistant isoniazid pellets reduced degradation of rifampicin in acidic medium
}

\author{
Fátima Duarte Freire ${ }^{1}$, Manuela Bernardo Câmara ${ }^{1}$, Monique Gomes Dantas ${ }^{1}$, \\ Cícero Flávio Soares Aragão ${ }^{2}$, Túlio Flávio Accioly de Lima e Moura ${ }^{2}$, Fernanda Nervo Raffinn ${ }^{2, *}$
}

\begin{abstract}
${ }^{1}$ Pharmaceutical Development Laboratory, Graduate Program in Pharmaceutic Sciences, Federal University of Rio Grande do Norte, Natal, RN, Brazil, ${ }^{2}$ Pharmaceutical Development Laboratory, Pharmacy Department, Federal University of Rio Grande do Norte, Natal, RN, Brazil
\end{abstract}

\begin{abstract}
Isoniazid and rifampicin are considered the first-line medication for preventing and treating tuberculosis. Rifampicin is degraded in the stomach acidic environment, especially when combined with isoniazid, factor contributing to treatment failure. In this study, gastric-resistant isoniazid pellets were obtained to physical contact of this drug with rifampicin and to bypass the stomach's acidic environment. The pellets were fabricated using the extrusion-spheronization technique. The coating process was conducted in a fluid spray coater using Acrycoat L $100^{\circledR}$ solution as the coating agent. The pellets obtained were submitted to a dissolution test in $\mathrm{HCl} 0.1 \mathrm{~N}$ and phosphate buffer media. The results indicated that optimum gastric-resistance was only attained with the highest amount of coating material, with isoniazid almost fully released in phosphate buffer. The amount of rifampicin released from its mixture with non-coated isoniazid pellets in $\mathrm{HCl} 0.1 \mathrm{~N}$ was less than that released from its mixture with the entericcoated pellets. Acrycoat L $100^{\circledR}$ was shown to be an effective enteric/gastric-resistant coating since the stability of rifampicin appeared to be enhanced when physical contact of this drug with isoniazid was prevented at low $\mathrm{pH}$.
\end{abstract}

Uniterms: Rifampicin. Gastric-resistant isoniazids/pellets. Pellets/enteric coating. Acrycoat L 100®/ use/enteric coating.

Isoniazida e rifampicina são fármacos de primeira escolha para a prevenção e tratamento da tuberculose. A rifampicina degrada-se em condições ácidas do estômago, principalmente na presença da isoniazida, o que contribui para a falha do tratamento. O presente trabalho teve como objetivo a obtenção de péletes de isoniazida gastrorresistentes, visando a evitar contato da rifampicina com isoniazida e consequente degradação no meio ácido estomacal. Os péletes foram produzidos pela técnica de extrusão-esferonização. O processo de revestimento foi conduzido em leito fluidizado com solução orgânica de Acrycoat L $100^{\circledR}$.

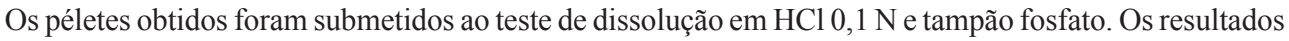
indicam que a gastrorresistência foi obtida somente com a maior quantidade de revestimento, sendo a isoniazida liberada completamente no meio tampão fosfato. A quantidade de rifampicina dissolvida em meio ácido, quando associada a péletes de isoniazida não revestidos, foi menor do que a observada na presença de péletes de liberação entérica. O polímero Acrycoat L 100® mostrou-se eficiente para o recobrimento com a função de gastrorresistência, indicando que a instabilidade da rifampicina pode ser reduzida nas associações com a isoniazida através do revestimento entérico da isoniazida.

Unitermos: Rifampicina. Isoniazidas gastrorresistentes/péletes. Péletes/revestimento entérico. Acrycoat L $100 \circledR /$ uso/revestimento entérico.

\footnotetext{
*Correspondence: F. N. Raffin. Laboratório de Desenvolvimento de Medicamentos, Universidade Federal do Rio Grande do Norte. Rua Brigadeiro Cordeiro de Farias, s/n, Petrópolis, 59010-180 - Natal - RN, Brasil. E-mail: feraffin@ufrnet.br
} 


\section{INTRODUCTION}

Tuberculosis is one of the most common causes of infectious, disease-related mortality worldwide. Factors such as lack of patient compliance to the treatment regimen (which can take up to 9 months), development of multiresistant microorganisms and co-infection with the human immunodeficiency virus (HIV) have contributed to the failure of medical treatment and to increased mortality rates. In fact, multidrug-resistant tuberculosis remains the main cause of death among patients with HIV (WHO, 2011).

The World Health Organization (WHO) and the International Union Against Tuberculosis and Lung Disease recommend the use of fixed doses of the firstline drugs for tuberculosis treatment: rifampicin (RMP), isoniazid, (INH) pyrazinamide (PYR) and ethambutol $(\mathrm{ETH})$ in order to assure adequate treatment (WHO, 2011). However, rifampicin degrades in an acidic medium, especially when associated with isoniazid. RMP undergoes hydrolysis in an acid $\mathrm{pH}$ leading to 3-formylrifamycin (3-FRSV), which is poorly absorbed. In addition, this compound reacts with INH forming isonicotinyl hydrazone (HYD). HYD converts back to INH and 3-FRSV resulting in significant recovery of INH with an eventual loss of RMP. The degradation rate of RMP was shown to be higher in the presence of INH in $\mathrm{HCl}$ $0.1 \mathrm{~N}$ and simulated gastric fluid. Consequently, the dose available for absorption is significantly decreased (Shishoo et al., 1999; Singh et al., 2000, 2001).

The thermal behavior of binary mixtures of rifampicin and isoniazid polymorphic forms (I and II) has been determined by differential scanning calorimetry (DSC). The results showed that the different rifampicin polymorphic forms interacted with isoniazid. In addition, the mixture of both drugs became more thermally stable than each drug individually (Freire et al., 2009).

In order to overcome the reduction in bioavailability of rifampicin when associated with isoniazid, the development of a formulation that can minimize the interaction of these drugs in the GI tract appears to be a reasonable alternative. For this purpose, several delivery systems have been developed aiming to control the time and site of rifampicin/isoniazid delivery.

Alginate hydrogels have been used to produce microparticles for controlled release of rifampicin, isoniazid and pyrazinamide, whose release profiles have been determined in vitro and in vivo. It was shown that the bioavailability of these drugs was about 9 times higher than those of the non-encapsulated forms (Qurrat-Ul-Ain et al., 2003).
It has been reported that rifampicin is well absorbed from the stomach due to its maximum solubility in the $\mathrm{pH}$ range of 1-2, whereas isoniazid is less permeable through the stomach, but well absorbed from all three segments of the intestine (Shishoo et al., 1999). Therefore, the distinct physicochemical properties of these drugs, especially in terms of solubility and stability at different $\mathrm{pH}$ values, suggests that delivering each compound at different sites in the GI tract would be advantageous.

Gastric-resistant coatings, also called enteric coatings, have been used in oral solid dosage forms to overcome problems such as gastric mucosal irritation, poor oral bioavailability and incompatibility with other components in the formulation (Lecomte et al., 2003). Gastric-resistant coatings are typically made from polymers whose solubility is $\mathrm{pH}$ dependent. Cellulose phthalates (acetate phthalate and hydroxypropyl methyl phthalate), polyvinyl phthalates, as well as polyacrylates and methacrylates (Eudragit and Acrycoat) are all insoluble in the acidic $\mathrm{pH}$ of the stomach and have been extensively used as enteric coatings (USP, 2007).

Gastric-resistant minitablets of isoniazid have been prepared using an organic solution of hydroxypropyl methylcellulose phthalate (HPMCP) as an enteric coating. The optimum formulation showed an acid resistance of two hours, while $90 \%$ of isoniazid was released within 15 minutes in phosphate buffer $\mathrm{pH}$ 7.4. The performance of the enteric coating proved to be influenced by the amount of HPMCP in the nuclei as well as in the coating (Gohel, Sarvaiya, 2008).

A novel dosage form has been developed where two gastro retentive tablets of rifampicin and one entericcoated capsule of isoniazid, were placed in a hard gelatin capsule. The results showed that more than $90 \%$ of isoniazid was released within 30 minutes in an alkaline medium, whereas rifampicin was released over 4 hours. Moreover, since the physical contact between these drugs was reduced, the degradation of rifampicin was minimized (Gohel, Sarvaiya, 2007).

In another study, isoniazid pellets were coated with an aqueous suspension of Sureteric ${ }^{\circledR}$ resulting in only $10 \%$ isoniazid release in $\mathrm{HCl} 0.1 \mathrm{~N}$ over 120 minutes. However, the stability of rifampicin in these gastric-resistant pellets was not evaluated (Punda et al., 2010). In addition, Bhise et al., (2010) demonstrated that microspheres with high polymer content protected rifampicin from degradation in an acidic medium.

Thus, the aim of this study was to prepare gastricresistant isoniazid pellets to prevent direct physical contact between rifampicin and isoniazid and to investigate the 
effectiveness of this formulation in reducing rifampicin degradation in an acidic medium.

\section{MATERIAL AND METHODS}

The following material was used: isoniazid (Zheijiang Jiangbei Pharm. Co, 20060707), rifampicin (Louhe Nanjiecun phar.G.P., 0710047), microcrystalline cellulose 101 (Blanver, 362/05) Acrycoat and Methocel E6. The other reagents were of analytical grade and used as received.

\section{Preparation of isoniazid-containing pellets}

Pellets were prepared by the extrusion-spheronization technique, where isoniazid and microcrystalline cellulose 101 (85:15 weight ratio) were mixed in planetary mixer for 5 minutes. After the mixture was sieved through a $1.0 \mathrm{~mm}$ mesh, an aqueous solution of Methocel E6 1\% $(\mathrm{w} / \mathrm{v})$ was slowly added until a wet mass was obtained. The wet mass was then extruded using a radial extruder fitted with a screen having $1.0 \mathrm{~mm}$ diameter holes at $50 \mathrm{rpm}$. The extrudate was spheronized for $3 \mathrm{~min}$ in a spheronizer at a rotation speed of $800 \mathrm{rpm}$. The pellets thus obtained were dried in a fluidized bed to about $1.5 \%$ moisture. Further, the pellets were sieved and particles of $1.0 \mathrm{~mm}$ in diameter were selected for the coating process. Bulk and tapped density, Carr index, Hausner factor, angle of repose and friability were determined according to the USP 30 procedures and were used to characterize the pellets (USP, 2007).

\section{Coating of pellets}

The coating solution was obtained by dissolving the polymer Acrycoat L $100^{\circledR}$ in an isopropanol/ethanol mixture 1:1 (v:v) under magnetic stirring. Subsequently, triethyl citrate was added and the mixture stirred for an additional 10 minutes. The coating process was performed in a fluidized bed at inlet and atomizing pressures of 2.5 and 2.0 bar, respectively; inlet and outlet air temperatures were $50{ }^{\circ} \mathrm{C}$ and $37{ }^{\circ} \mathrm{C}$, respectively. The volume of the coating solution was previously adjusted to yield $15 \%$, $25 \%$ and $50 \%$ on weight increase with respect to the nuclei's weight.

\section{Dissolution of isoniazid pellets}

Dissolution studies were carried out following the USP Dissolution Method for Extended Release. Accurately weighed pellets containing the equivalent of $200 \mathrm{mg}$ of isoniazid $(270.6,294.1$ and $353 \mathrm{mg}$ for the pellets with 15,25 and $50 \%$ in weight increase, respectively) were transferred to hard gelatin capsules (size 00). The dissolution apparatus I (ERWEKA DT6) was used to perform the dissolution tests at $37^{\circ} \mathrm{C}$ and a rotation speed of $100 \mathrm{rpm}$. In order to simulate the GI tract conditions, the dissolution tests were first carried out in media at $\mathrm{pH} 1.2$ $(\mathrm{HCl} 0.1 \mathrm{~N})$ and then at $\mathrm{pH} 6.8$ (phosphate buffer), where the samples were allowed to remain in contact with each medium for 2 hours. Aliquots of $15 \mathrm{~mL}$ were withdrawn at 60 and 120 minutes in $\mathrm{pH} 1.2$ and at 15,30 and 45 minutes in $\mathrm{pH}$ 6.8. After proper dilution, the amount of isoniazid was determined spectrophotometrically at $263 \mathrm{~nm}$ using a UV-vis spectrophotometer (VARIAN, CARY-50).

\section{Dissolution of rifampicin in the presence of isoniazid pellets}

In order to evaluate the influence of the presence of isoniazid on the dissolution of rifampicin in acidic medium, accurately weighed pellets (with and without coating) containing the equivalent of $200 \mathrm{mg}$ of isoniazid were mixed with $300 \mathrm{mg}$ of rifampicin and transferred to hard gelatin capsules (size 00 ). In addition, the effectiveness of the enteric coating in preventing the interaction of isoniazid with rifampicin was also evaluated. The release of both drugs was measured using the same apparatus and procedure described in the previous section with some minor modifications. Aliquots were withdrawn from the acidic medium $(\mathrm{HCl} 0.1 \mathrm{~N})$ at $10,15,20,30,45$ and 60 minutes and the absorbance of the diluted solution measured by Ultra Fast Liquid Chromatography - tandem Diode Array Detection (UFLC/DAD) (Amorim, 2013).

A buffer solution composed of $50 \mathrm{~g}$ of ammonium acetate and $0.2 \mathrm{~g}$ of copper II acetate monohydrate diluted in $1.0 \mathrm{~L}$ water was freshly prepared, $\mathrm{pH}$ adjusted to 5.0 using glacial acetic acid, mixed, filtered and degassed. The mobile phase was composed of two solutions: (A) buffer solution and methanol $(94: 6, \mathrm{v} / \mathrm{v})$ from zero to $1.9 \mathrm{~min}$ and (B) buffer solution and acetonitrile $(55: 45, \mathrm{v} / \mathrm{v})$, from 2 to $4 \mathrm{~min}$; both solutions were filtered and degassed. Standard and sample solutions were injected $(2 \mu \mathrm{L})$ into the chromatograph after Millipore Millex-HV filtration $(0.22 \mu \mathrm{m})$. The chromatographic UPLC XR analyses were performed by a Shimadzu device equipped with binary pump LC020AD XR, auto-sampler SIL-20AC XR, oven column CTO-20AC, and PDA detector SPD-M20A. In this study, a Shim-pack XR-ODS column (30 mm x 2 mm i.d., $2.2 \mu \mathrm{m}$ particle size) was used and the test performed at $30^{\circ} \mathrm{C}$, at a wavelength of $254 \mathrm{~nm}$ and flow rate of $0.2 \mathrm{~mL} / \mathrm{min}$ (Amorim, 2013). 
The dissolution profiles were compared based on the area under the curve (AUC) values obtained for RMP curves in the presence of coated and uncoated INH pellets, after integration from zero to $60 \mathrm{~min}$.

\section{RESULTS AND DISCUSSION}

Rifampicin is well absorbed in the stomach due to its good solubility in the 1-2 $\mathrm{pH}$ range. On the other hand, the absorption of isoniazid at this $\mathrm{pH}$ is extremely poor, while most of its content is absorbed in the intestine (Shishoo, 1999). Therefore, an alternative to reduce the degradation of rifampicin in the presence of isoniazid is the prevention of physical contact between these drugs, which can be achieved by enteric-coating of isoniazid. This approach would lead to the release of these drugs at different sites along the GI tract.

Although microparticulate systems represent a more costly and time consuming alternative, they have several advantages over regular dosage forms, such as a uniform and faster distribution over a larger GI area, as well as less variation in gastric residence time. These factors contribute to more uniform bioavailability among individuals and help reduce the risk of toxicity (Vervaet, Baert, Remon, 1995; Gandhi, Kaul, Panchagnula, 1999).

The pelletization technique produces spherical particles with different sizes and reasonable mechanical strength, where the experimental parameters can strongly influence the quality of the pellets and the success of the coating process (Feldon, McGinity, 2005).

In this study, the pellets obtained had a spherical and relatively regular shape (Figure 1), which resulted in good flow properties and narrow particle size distribution. These are desirable properties for coating.

Table I summarizes the results of non-coated pellet characterization, including bulk and tapped density,

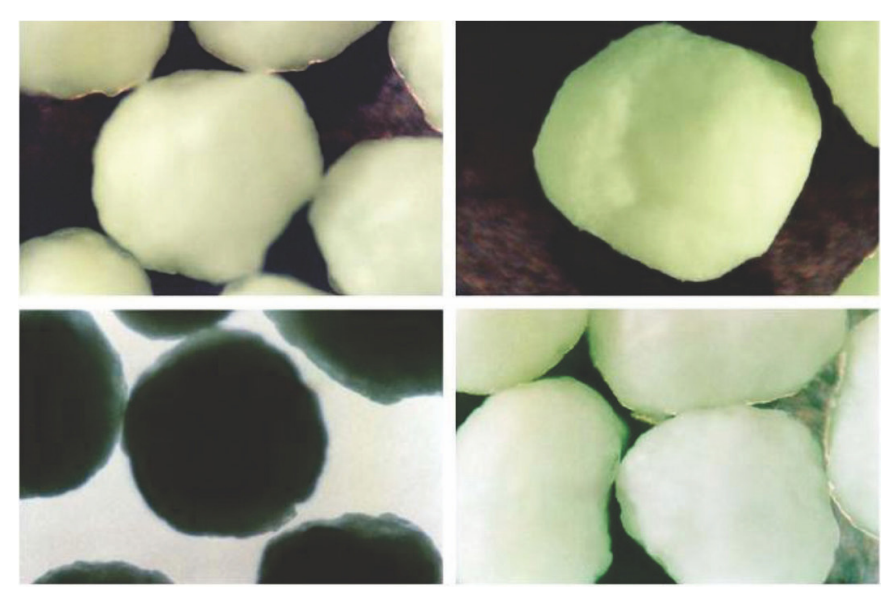

FIGURE 1 - Micrographs of isoniazid pellets.
TABLE I - Characterization of the non-coated pellets

\begin{tabular}{lc}
\hline Parameters & Measured values \\
\hline Bulk density & $0.668 \mathrm{~g} / \mathrm{mL}$ \\
Tapped density & $0.690 \mathrm{~g} / \mathrm{mL}$ \\
Hausner factor & 1.03 \\
Carr index & $3.1 \%$ \\
Angle of repose & $17.6^{\circ}$ \\
Flow rate & $30 \mathrm{~g} / \mathrm{s}$ \\
Friability & $0.5 \%$ \\
\hline
\end{tabular}

Hausner factor, Carr index, angle of repose, flow rate and friability.

In order to achieve successful pellet coating, the values of bulk and tapped densities should be as close as possible because a large difference between these values can lead to considerable variation in the amount of material that needed for coating (Lecomte et al., 2003; Vervaet, Baert, Remon, 1995; Gandhi, Kaul, Panchagnula, 1999). In this study, comparison of the bulk and tapped densities indicates that the difference was relatively low. Moreover, the values of Hausner factor, Carr index and angle of repose indicate that the pellets have reasonable flow characteristics, which could be attributed to the pellets' spherical shape. On the friability test, the pellets showed a weight loss of $<1.5 \%$, considered an optimum value for tablets. In fact, mechanically-resistant pellets are advantageous as they are expected to retain their physical integrity during the coating process (Lecomte et al., 2003; Vervaet, Baert, Remon, 1995; Gandhi, Kaul, Panchagnula, 1999). Besides the amount of polymer solution (coating solution), the injection conditions are equally important in assuring a homogeneous coating layer on the nuclei, which can ultimately lead to more uniform drug release (Feldon, McGinity, 2005). The coated pellets had the same quality as the uncoated pellets.

In this study, the release profiles for non-coated and coated isoniazid pellets at $\mathrm{pH} 1.2$ and 6.8 (simulating stomach and intestine, respectively) are shown in Figure 2.

As can be seen in Figure 2, the amount of isoniazid released from the non-coated pellets was higher than that released from the coated counterparts, where about $90 \%$ of the total drug content was released within the first 20 minutes of the experiment, which appears to indicate that the nuclei did not interfere with drug release. On the other hand, as the amount of Acrycoat L 100 was increased on the pellets, the lag time for isoniazid release was increased. The pellets coated with lower amounts of polymer ( 15 and $25 \%$ in weight increase) were not completely resistant at the stomach's pH since 49.5 and $13.8 \%$ of the drug, 


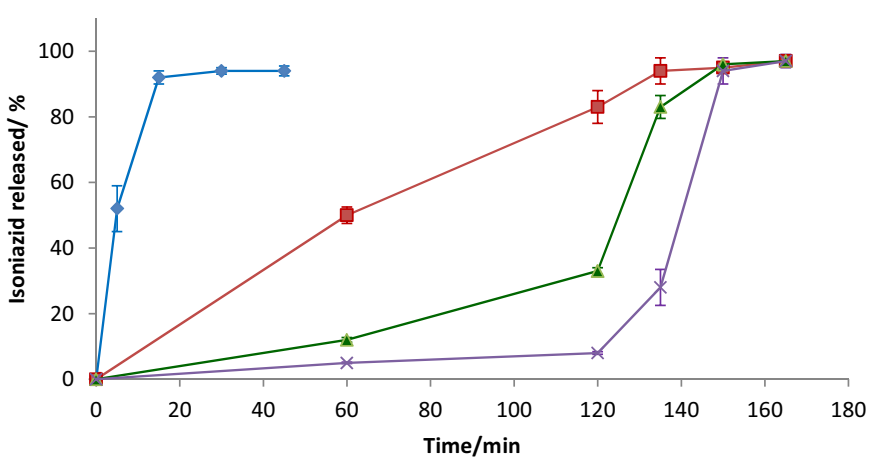

FIGURE 2 - Release of isoniazid from $(\bullet)$ non-coated pellets, and from those coated with Acrycoat L 100: (口) 15\%, ( $\boldsymbol{\Delta}$ ) $25 \%$ and $(\times) 50 \%$ (from 0 to $120 \mathrm{~min}$ : $\mathrm{pH}=1.2$; from 120 to 180 min: $\mathrm{pH}=6.8$ ).

respectively, was released at 60 minutes of the experiment, whereas 85 and $37 \%$ was released within 2 hours. These values do not meet the USP standards for isoniazid release from gastric-resistant dosage forms.

When the volume of coating solution was increased (yielding a 50\% weight increase) the amount of isoniazid released in $\mathrm{HCl} 0.1 \mathrm{~N}$ was $\sim 5.5 \%$ in 2 hours, which is in accordance with the USP 30 limits. On the other hand, after 45 minutes in phosphate buffer solution, $99.72 \%$ of this drug was released, which is above the minimum of $80 \%$ established by the USP. This is due to the fact that $\mathrm{pH}$-sensitive Acrycoat L 100 is ionized and solubilized at the intestine's pH. Acrycoat L $100^{\circledR}$ is a copolymer of methacrylic acid Type A, which is soluble in intestinal fluids, whose $\mathrm{pH}$ is above 6 . Due to the methyl groups in its structure, methacrylic acid is a weak acid (pKa 4.66), which means that the coatings made of Acrycoat $\mathrm{L}$ $100^{\circledR}$ are not ionized and hence poorly soluble at low $\mathrm{pH}$ (Lecomte et al., 2003; Feldon, McGinity, 2005).

In addition, our findings clearly show that the thickness of Acrycoat L 100 coating is an effective factor for resistance to dissolution at low $\mathrm{pH}$. In fact, similar results were obtained when para-aminosalicylate pellets coated with Eudragit L-30 and D-55 (copolymer of methacrylic acid Type C) were prepared to eliminate the drug's side effects and prevent its degradation at low $\mathrm{pH}$. The polymer solution was able to coat the pellets yielding an increase in final weight of 40,50 and $60 \%$, where the latter sample was the most effective for reducing degradation of the drug (Siepmann et al., 2005).

Since our studies show that the pellets coated with the higher amount of Acrycoat L $100^{\circledR}$ were the most effective for preventing isoniazid release to the acidic medium, it was decided to use this concentration to prepare additional isoniazid-containing pellets and perform dissolution tests with rifampicin in the presence of these pellets. The objective of this experiment was to compare the amount of rifampicin released from its mixture with non-coated isoniazid pellets against that released from its mixture with enteric-coated isoniazid samples. The UPLC method was used to detect possible degradation of RMP (Amorim, 2013).

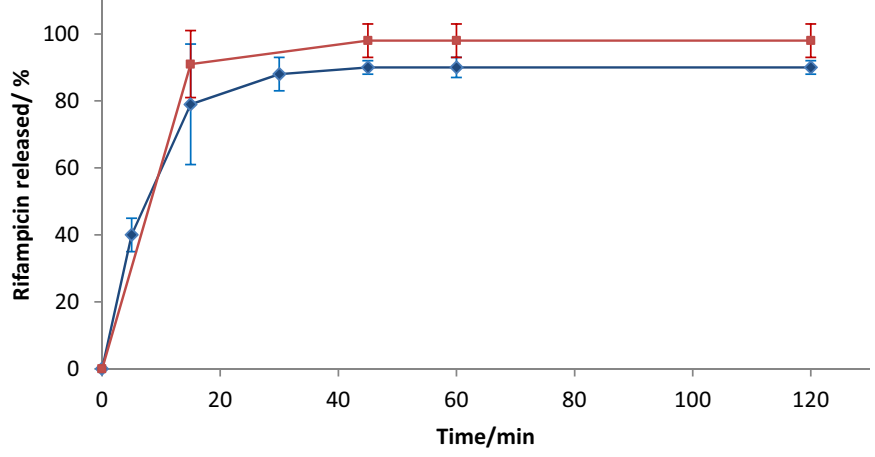

FIGURE 3 - Dissolution of rifampicin in the presence of non-coated and $(\square)$ enteric-coated isoniazid pellets.

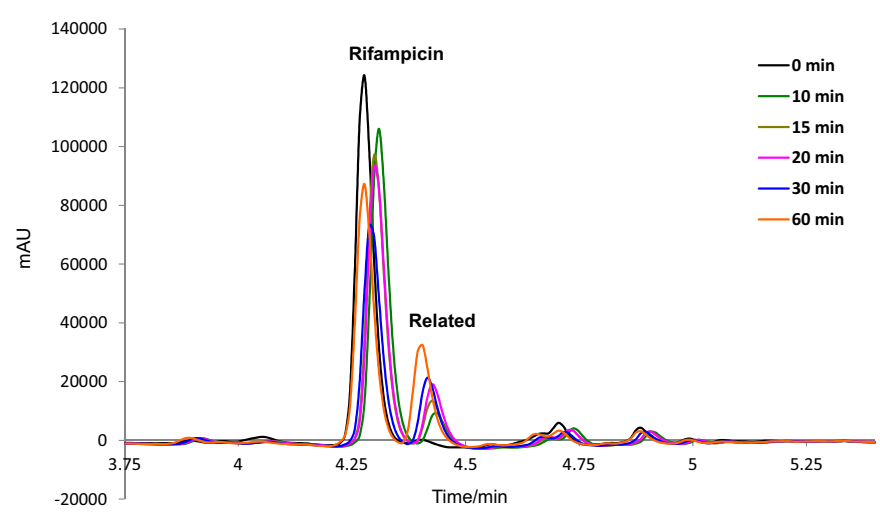

FIGURE 4 - UFLC/DAD chromatograms obtained during dissolution of rifampicin in the presence of non-coated isoniazid pellets.

Figure 3 shows the dissolution profiles of rifampicin from its mixture with non-coated and enteric-coated isoniazid pellets. As can be observed, RMP release from the capsules containing uncoated INH pellets reached $80 \%$ at $15 \mathrm{~min}$, and then RMP concentration decreased in the dissolution medium. In the presence of enteric-coated pellets, INH is not released to the medium (Figure 2) and RMP concentration remains higher comparing both profiles. AUC values calculated for the curves were 3951.77 and 4406.99 respectively, indicating that when RMP/INH contact was avoided, the AUC increased by $11.5 \%$.

Furthermore, the chromatograms obtained by UFLC/DAD at each time point of the dissolution profile of 
rifampicin in the presence of non-coated isoniazid pellets show the reduction of RMP peak area and formation of a related product with time, a finding not observed in the presence of the coated pellets. This result is in agreement with the findings of Shishoo et al. (1999), who showed that $12 \%$ of rifampicin was degraded to 3-formil-rifampicin (3-FRSV) in acidic medium after 45 minutes on the dissolution test, whereas $21 \%$ of this drug was degraded in the presence of isoniazid under the same experimental conditions. Another study corroborated these findings by showing that the bioavailability of rifampicin was significantly reduced in the presence of isoniazid (Rahman, Ali, 2008).

Our results suggest that an interaction between isoniazid and rifampicin took place when both drugs were in contact with each other at low $\mathrm{pH}$. Thus, enteric coating of isoniazid pellets appears to be an effective way of reducing its physical contact with rifampicin in the stomach. Acrycoat L $100^{\circledR}$ was shown to be effective as an enteric-coating material, representing a promising alternative to overcome the reduction in rifampicin's bioavailability. Capsules containing rifampicin pellets for release in an acidic $\mathrm{pH}$ are being developed at our lab, where they will be fabricated using a one-way process.

\section{CONCLUSIONS}

In conclusion, the effectiveness of Acrycoat L $100^{\circledR}$ coatings in protecting isoniazid from acid degradation was strongly influenced by the amount used in the pellets obtained, where the extent of isoniazid dissolution established by the USP 30 was only achieved with higher amounts of Acrycoat L $100^{\circledR}$ solutions (sufficient to yield a $50 \%$ weight increase over non-coated pellets).

The extent of rifampicin dissolution in acidic medium in the presence of non-coated isoniazid pellets was lower than that with coated isoniazid pellets, which suggests that the use of enteric coating decreased the release of isoniazid in $\mathrm{HCl} 0.1 \mathrm{~N}$ and reduced the availability of this drug to react with rifampicin, which led to a decrease in rifampicin degradation at low $\mathrm{pH}$.

\section{REFERENCES}

AMORIM, M.V.P. Otimização e validação de métodos analíticos para a determinação simultânea de tuberculostáticos (4 em 1) por CLAE/DAD e CLUE/DAD. Natal, 2013. 103 p. [Dissertation of Master degree. Center of Health Science. Federal University of Rio Grande do Norte].
BHISE, S.B.; MORE, A.B.; RAJKUMAR, M. Formulation and in vitro evaluation of rifampicin loaded porous microspheres. Sci. Pharm., v.78, n.2, p.291-302, 2010.

FELDON, L.A.; McGINITY, J.W. Enteric film coating of soft capsules. 2005. Available at: <www.colorcom.com/ pharma $>$. Accessed on: 15 July 2005.

FREIRE, F.D.; ARAGÃO, C.F.S.; MOURA, T.F.A.L.; RAFFIN, F.N. Thermal studies of isoniazid and mixtures with rifampicin. J. Therm. Anal. Calorim., v.97, p.333-336, 2009.

GANDHI, R.; KAUL, C.L.; PANCHAGNULA, R. Extrusion and spheronization in the development of oral controlledrelease dosage forms. Pharm. Sci. Technol. Today, v.2, n.4, p.160-170, 1999.

GOHEL, M.C.; SARVAIYA, K.G. A Novel solid dosage form of rifampicin and isoniazid with improved functionality. AAPS PharmSciTech., v.8, n.3, p.E133-E139, 2007.

GOHEL, M.C.; SARVAYA, K.G. Exploration of cold extrusion for the preparation of enteric minitablets of isoniazid. Indian J. Pharm. Sci., v.70, p.298-302, 2008.

LECOMTE, F.; SIEPMANN, J.; WALTHER, M.; MAcRAE, R.J.; BODMEIER, R. Blends of enteric and GTIinsoluble polymers used for film coating: physicochemical characterization and drug release patterns. J. Control. Release, v.89, n.3, p.457-471, 2003.

PUNDA, S.; JOSHI, A.; VASU, K.; NIVSARKAR, M.; SHISHOO, C. Multivariate optimization of formulation and process variables influencing physico-mechanical characteristics of site-specific release isoniazid pellets. Int. J. Pharm., v.388, p.64-72, 2010.

QURRAT-Ul-AIN; SHARMA, S.; KHULLER, G.K.; GARG, S.K. Alginate-based oral drug delivery system for tuberculosis: pharmacokinetics and therapeutic effects. $J$. Antimicrob. Chemother., v.51, n.4, p.931-938, 2003.

RAHMAN, M.D.A.; ALI, J. Development and in vitro evaluation of enteric coated multiparticulate system for resistant tuberculosis. Indian J. Pharm. Sci., v.70, n.4, p.477-481, 2008.

SHISHOO, C.J.; SHAH, S.A.; RATHOD, I.S.; SAVALE, S.S.; KOTECHA, J.S.; SHAH, P.B. Stability of rifampicin in dissolution medium in presence of isoniazid. Int. J. Pharm., v.190, n.1, p.109-123, 1999. 
SIEPMANN, F.J.; SIEPMANN, M.; WALTHER, R.J.; MAcKAE, R. BODMEIER. Blends of aqueus polymer dispersions used for pellet coating: Importance of the particle size. J. Control. Release, v.105, n.3, p.226-239, 2005.

SINGH, S.; MARIAPPAN, T.T.; SANKAR, R.; SARDA, N.; SINGH, B. A critical review of the probable reasons for the poor/variable bioavailability of rifampicin from antitubercular fixed-dose combination (FDC) products, and the likely solutions to the problem. Int. J. Pharm., v.228, n.1-2, p.5-17, 2001.

SINGH, S.; MARIAPPAN, T.T.; SHARDA, N.; SINGH, B. Degradation of rifampicin, isoniazid and pyrazinamide from prepared mixtures and marketed single and combination products under acid conditions. Pharm. Pharmacol. Commun., v.6, p.491-494, 2000.
UNITED STATES PHARMACOPEIA. USP. 30ed. Rockville: USP Convention, 2007.

VERVAET, C.; BAERT, L.; REMON, J.P. Extrusionspheronization: literature rewiew. Int. J. Pharm., v.116, p.131-146, 1995.

WORLD HEALTH ORGANIZATION. WHO. Global tuberculosis control report. WHO, 2011. Available at: $<$ www.who.int/publications $>$. Accessed on: Jan. 2012.

Received for publication on $12^{\text {th }}$ March 2013 Accepted for publication on $18^{\text {th }}$ June 2014 
